Please ensure that your abstract fits into one column on one page and complies with the Instructions to Authors available from the Abstract Submission web page.

\title{
Trophic structure and HBCD biomagnification in a marine foodweb from aquaculture farm, South Korea
}

\author{
MIN-SEOB KIM ${ }^{1,2}$, SEJIN PARK ${ }^{2}$, JIYOUNG SON ${ }^{2}$, \\ WONCHAN LEE ${ }^{2}$, JONGWOO CHOI ${ }^{1}$, KYUMGHOON SHIN ${ }^{3}$, \\ MINKYU CHOI ${ }^{*}$ \\ ${ }^{1}$ Environmental Measurement \& Analysis Center, NIER, \\ Incheon 22689, Rep. of Korea, \\ ${ }^{2}$ Marine Environment Research Devision, NIFS, Busan 46083, \\ Rep. of Korea, \\ ${ }^{3}$ Department of Marine Sciences and Convergent Technology, \\ Hanyang University, Ansan 15588, Rep. of Korea, \\ candyfrog77@gmail.com
}

Hexabromocyclododecanes (HBCD) is a widely used brominated flame retardants globally, and has been found widely distributed in the environment. Many HBCD sources are located at the southern coast and the released HBCD may enter into the coastal ecosystem. There is a harmful effect that HBCD can transfer through the food web to the diet of human. Therefore, it is important to trace the contamination in the organisms for food safety and human health as a further investigation. The main objectives of this study here: (1) to examine the levels of HBCD diastereoisomers $(\alpha-, \beta-, \gamma-$ HBCD) in fish collected from the coast; (2) to illustrate the trophic transfer of HBCD and the impact from the marine food web structure; (3) to assess the dietary exposure of HBCD via consumption of the fish for the human. Variation was observed for the bioaccumulation of HBCD between the detrital food chain and grazing food chain. In the studied species, the anchovy was most contaminated which may be caused by its feeding on detritus. At the same time, the transfer of HBCD along the food web was investigated, and $\mathrm{HBCD}$ was biomagnified from the prey to the predator in the grazing food chains. Among the three diastereoisomers, $\alpha$ HBCD was biomagnified with increasing trophic levels in the food web while $\beta$-HBCD and $\gamma$-HBCD were not. To the best of our knowledge, this is the first study to examine the HBCD biomagnification for both fish and marine invertebrate through stable isotope analysis in aquaculture farm. 